\title{
Endoscopic characterization and resection of Vanek's tumor of the duodenum
}
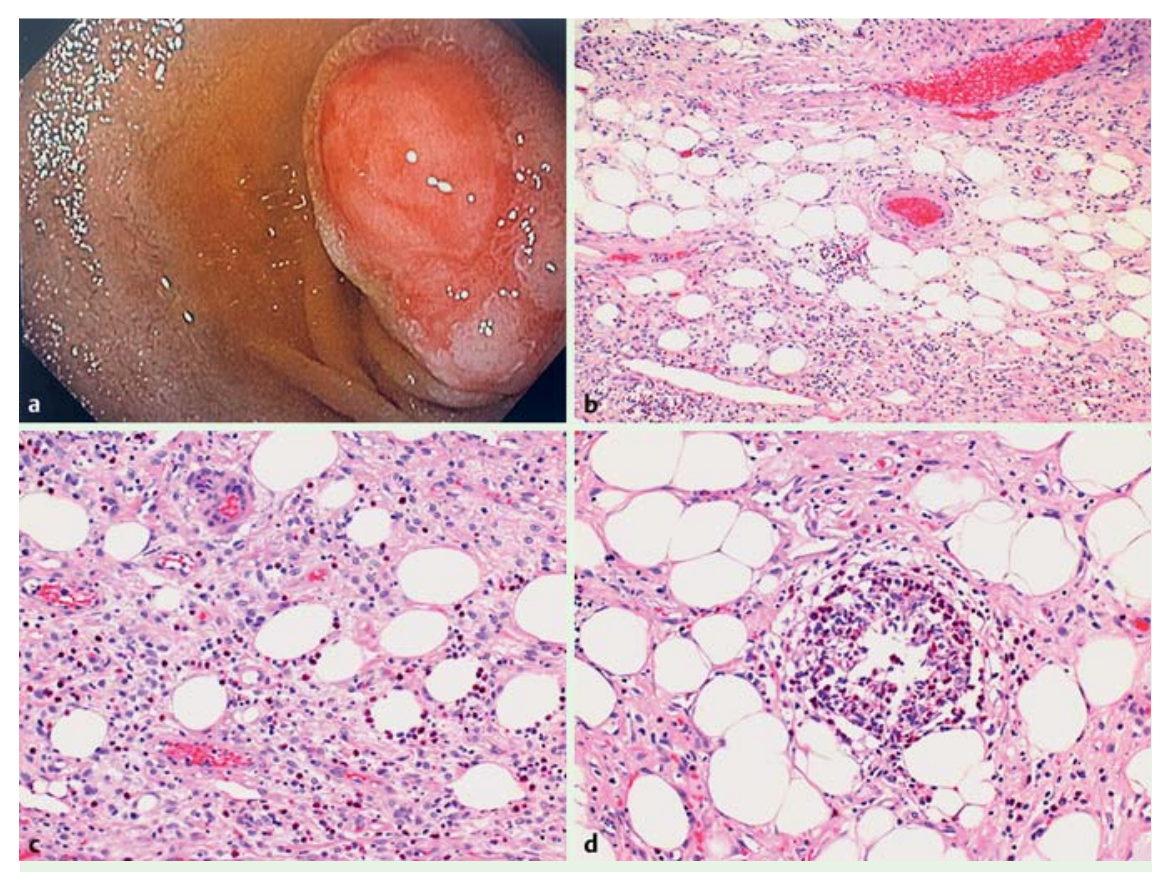

Fig. 1 Duodenal inflammatory fibroid polyp (IFP). a A pedunculated, ulcerated, polypoid lesion was located between the first and second duodenum. The base of the lesion was long, soft, and pedunculated. On endosonography there were no signs of muscular involvement. b Histology revealed a lesion consisting mostly of submucosa. $\mathbf{c}$ The lesion also contained intermingled fibrous and adipose tissue and spindle cells. c, d A marked increase in acute and chronic inflammatory cells, particularly eosinophils, was also observed. This eosinophilic infiltrate intermixed with intermingled fibrous and adipose tissue is characteristic of IFP (Vanek's tumor).

A 66-year-old white man was referred following visualization of a duodenal mass on endoscopy. The patient had presented to his primary physician complaining of a 6-week history of nausea, vomiting, 20-pound unintentional weight loss, and melena. Initial physical exam revealed diffuse abdominal pain. Laboratory work-up revealed normocytic-normochromic anemia (Hb 9.4g/dL), abdominal ultrasound showed a distended gallbladder, and abdominal computed tomography scan findings were negative. Esophagogastroduodenoscopy (EGD) revealed a bleeding pedunculated lesion $(2 \times 2 \mathrm{~cm})$ in the duodenum. The lesion was injected with epinephrine $1: 10000$, and the patient was referred to our center, the University of Alabama at Birmingham Hospital.
Repeat EGD revealed a superficially ulcerated semipedunculated lesion ( $\boldsymbol{O}$ Fig. $\mathbf{1}$ a). The lesion was resected using advanced resection techniques, and the defect was closed using two clips. Key steps in the resection were creation of an adequate submucosal cushion, lifting of the lesion, incising around the base using endoscopic submucosal dissection techniques, and performing endoscopic mucosal resection. Histopathology revealed an inflammatory fibroid polyp (IFP), or Vanek's tumor, with free margins (R0) ( 0 Fig. 1 b-d). The patient had a satisfactory postoperative course, and remained asymptomatic at the 6-month follow-up.

This case is of interest for several reasons. First, it demonstrates IFP in the duodenum, which is rare. IFPs are rare submucosal lesions arising from a reactive, be- nign, granuloma-like process of the gastrointestinal tract $[1,2]$. Common locations include the stomach $(70 \%)$, ileum (19\%), and colon $(6 \%)[3,4]$, but occurrence in the duodenum is rare $[3,4]$. Second, a detailed endoscopic image of this tumor was obtained. Most previous publications lack endoscopic documentation. IFPs are semipedunculated or sessile lesions covered by normal mucosa with occasional superficial ulceration, and measure $2-5 \mathrm{~cm}$ in diameter [4,5]. Microscopically, they contain spindle cells, vascular and fibroblastic proliferation, with eosinophilic infiltration. Immunohistochemistry distinguishes them from gastrointestinal stromal tumors, as IFPs are CD-34 and vimentin positive but CD-117 negative. Finally, endoscopic resection was demonstrated to be effective in removing the IFP. However, larger lesions should be removed surgically.

In summary, this case demonstrated the endoscopic and histologic characteristics of duodenal IFP, and showed that endoscopic resection solves the partial gastric outlet obstruction and gastrointestinal bleeding.

Endoscopy_UCTN_Code_CCL_1AB_2AZ_3AB

Competing interests: None

\section{Paul T. Kröner ${ }^{1}$, Leona Council², Klaus Mönkemüller ${ }^{3}$}

${ }^{1}$ Department of Internal Medicine, Mount Sinai St. Luke's Roosevelt Hospital Center, New York, New York, United States

2 Department of Pathology, University of Alabama at Birmingham, Birmingham, Alabama, United States

${ }^{3}$ Basil I. Hirschowitz Endoscopic Center of Excellence, Division of Gastroenterology and Hepatology, University of Alabama at Birmingham, Birmingham, Alabama, United States

\section{References}

1 Wysocki AP, Taylor G, Windsor JA. Inflammatory fibroid polyps of the duodenum: a review of the literature. Dig Surg 2007; 24: $162-168$

2 VanekJ. Gastric submucosal granuloma with eosinophilic infiltration. Am J Pathol 1949; 25: $397-411$

3 Shimura T, Kataoka H, Sasaki M et al. Rectal inflammatory fibroid polyp resected with 
endoscopic submucosal dissection. Intern Med 2008; 47: 2029-2031

4 Akbulut S. Intussusception due to inflammatory fibroid polyp: a case report and comprehensive literature review. World J Gastroenterol 2012; 18: 5745 - 5752

5 Nomura M, Takahashi A, Takano $\mathrm{H}$ et al. Inflammatory fibroid polyp of the ileum which could be endoscopically diagnosed Dig Endosc 1991; 3: 102 - 108
Bibliography

DOI http://dx.doi.org/

10.1055/s-0034-1392595

Endoscopy 2015; 47: E408-E409

(c) Georg Thieme Verlag KG

Stuttgart · New York

ISSN 0013-726X

\section{Corresponding autho}

Paul T. Kröner, MD

Department of Internal Medicine Mount Sinai St. Luke's/Roosevelt Hospital Center 515 W 59th Street Apt. 15R

New York City

NY, 10019

USA

Fax: +1-212-523-4000

PFlorit@chpnet.org 